\title{
Determination of Potential Temperature and Density for Deep Fresh Waters*
}

\author{
Pavel P. Sherstyankin, Lubov N. Kuimova and Vladimir L. Potemkin \\ Limnological Institute, Siberian Division, Russian Academy of Sciences, Russia
}

\begin{abstract}
As a rule, the hydrodynamic modeling of processes in fresh waters is performed with the use of potential temperature $\theta$ and potential density $\rho^{*}$. However, the formulae of potential temperature for natural waters given by Phillips (1977), Gill (1982) and others take into account only adiabatic correction. They do not consider such important characteristics of natural waters as temperature of maximal density $T_{m d}(S, P)$ remoting of real temperatures $T(S, P)$ in situ from $T_{m d}\left(T=T-T_{m d}\right)$, changes of $T m d$ with decreasing of pressure $P($ depth $Z)$, and the equation of water state. $T_{m d}=T_{m d}(P)$ is the property of molecular structures of water (Horne, 1969). It is determined by the equation of water state: for example, for lacustrine waters in the form of Chen, Millero, (1986) $\rho=\rho(S, T, P)$, where $\rho, S$ are density and salinity natural water. There is given and discussed a new formula for the calculation of potential temperature. It is established that potential densities calculated according to the new formula suggested by us show the entire thermodynamic similarity of characteristics within $T$ in situ. It is not observed while using the old formulae.
\end{abstract}

Keywords: potential temperature, density, deep fresh waters, Lake Baikal

\section{Introduction}

The potential temperature $\theta(S, P)$ and potential density $\rho^{*}(S, P)$ are the most important oceanological and limnological characteristics for natural waters. There may occur greater difficulty and mistakes if the water temperature $T$ is close to the temperature of maximum density $T_{m d}$ especially in deep water. We have come to the conclusion that the formulae for the calculation of the potential temperature $\theta$ (Phillips, 1977; Gill, 1982) is not complete. Therefore, it gives incorrect results. In fact, the calculation of potential temperature $\theta(S, P)$ takes into account only adiabatic correction $\Delta T_{a d}(T, S, P)$ to temperature $T(S, P)$ measured in situ:

$$
\theta(T, S, P)=T\left(S, P_{a}\right)=T(S, P)+\Delta T_{a d}(T, S, P),
$$

where $P_{a}$ is the atmospheric pressure.

Let us prove that it is insufficiently for the reasonable determination $\theta(T, S, P)$.

\footnotetext{
*Received 1997-02-25; accepted 1998-03-27
} 


\section{Materials and Methods}

We make use of the experimentally-theoretical approach.

\section{Results}

\subsection{Theory}

In order to elucidate that phenomenon, let's consider $T$ as a function of $T_{m d}(S, P)$. At normal atmospheric pressure $\mathrm{Pa}$ it is about $4^{\circ} \mathrm{C}$, and decreases with the increase of pressure $P$ (or $Z$ ). This peculiarity is due to the molecular structures of the water (Horne, 1969). This function may be expressed as follows:

$$
T(S, P)=T_{m d}(S, P)+T(T, S, P)
$$

or

$$
T(T, S, P)=T(S, P)-\operatorname{Tmd}(\mathrm{S}, \mathrm{P}) .
$$

The absolute value of $T(T, S, P)$ increases when $T(S, P)$ becomes increasingly distant from $T_{m d}(S, P)$ while water density $\rho(T, S, P)$ or $\rho^{*}(S, P)$ decreases.

Let us consider three main characteristics of the equation $(2 b)$ :

1) Mathematically it involves any changes of $T_{m d}(S, P)$ with pressure $P$ (the depth $Z$ );

2) Its physical sense it allows one to take into account the water molecular structures of water determined by any particular equation of the water state (e.g., in the Chen-Millero (1986) form), as $T_{m d}(S, P)$ is determined only by the properties of molecular structures of water (Horne, 1969);

3 ) It is easy to obtain the potential temperature $\theta$ and $\theta$ for any pressure $P$ (or $Z$ ) using the equation (1), (2a) or (2b) (Kamenkovich, 1973; Gill, 1982). It is necessary to perform an adiabatic transition to the surface, to the atmospheric pressure $P_{a}(Z=0)$, i.e., the adiabatic correction $\Delta T_{a d}(T, S, P)$ should be taken into account:

$$
\theta(T, S, P)=\theta_{m d}\left(S, P_{a}\right)+\theta(T, S, P)
$$

or

$$
\theta(T, S, P)=\theta(T, S, P)-\theta_{m d}(S, P a),
$$

where $\theta(T, S, P)=T(T, S, P)+\Delta T_{a d}(T, S, P) ; \theta(T, S, P)$ - potential temperature for any $T, S$ and $P$; $\theta_{m d}(S, P a)$-potential temperature of maximal density for the atmospheric pressure $P_{a}(Z=0)$ circa $4^{\circ} \mathrm{C}$. Let us find the potential density $\rho^{*}(T, S, P)$ as (Kamenkovich, 1973; Gill, 1982)

$$
\rho^{*}(T, S, P)=\rho(\theta, S, P a) \text {. }
$$

Thus we deduce the main formulae for the potential temperature $\theta(T, S, P)$ in form $3 \mathrm{a}$ and $3 \mathrm{~b}$ and the potential density $\rho^{*}(T, S, P)$ and let us compare them with formulae different authors.

\subsection{Result of field observation}

It is very convenient to check our conclusions on Lake Baikal with its deepwater zone where the temperature is close to the temperature of maximum density, $T_{m d}(S, P)$ (Vereshagin, 1927; Weiss et al., 1991; Peeters et al., 1996). Let us take field observations with data of $\theta(T, S, P)$ and $\rho^{*}(T, S, P)$ and take only extreme points for deepwater zone by way of example of 300 and $1600 \mathrm{~m}$ (Fig.1.). 
We see that for deep water zone all $\theta(T, S, P)$ from data Weiss et al. (1991) and Peeters et al. (1996) are less than $4^{\circ} \mathrm{C}$ but our similar data are more than $4{ }^{\circ} \mathrm{C}$.

\section{Discussion}

According to a more complete identification of potential temperature $\theta(T, S, P)$ (Kamenkovich, 1973), "it is the temperature the system will get at equilibrium adiabatic transition from pressure $P$ to atmospheric pressure $P_{a}{ }^{\prime \prime}$.

The analysis shows that the equation (1) for the calculation of potential temperature $\theta(T, S, P)$ does not take into account the following characteristics: equilibrium transition; maximal density temperature $T_{m d}$ for natural waters; changes of $T_{m d}$ with pressure $P$ (depth $Z$ ), i.e. $T_{m d}=T_{m d}(S, P)$; remote of real temperature $T$ from $T_{\text {md }}$ or $T(S, P)=T(S, P)-T_{m d}(S, P)$; water state equation (Weiss et al., 1991; Sherstyankin, Kuimova, 1995; Peeters et al., 1996). The formula reveals only the features of the surface waters. The temperature of maximal density of the water Tmd(S,Pa) and its dependence on $\mathrm{P}$ are the properties of molecular structures of the water (Horne, 1969). It is calculated according to the equation of water state, e.g. for fresh waters (Chen, Millero, 1986), and it is not reduced to adiabatic corrections. The formal use of (1) results in incorrect determination of $\theta(T, S$, P).

To eliminate the deficiency mentioned above, it is necessary to transform (1) according into (2a). Then the equilibrium transition from pressure $P$ to $P_{a}$ is performed (it is shown with an arrow $P \rightarrow$ $\left.P_{a}\right) . T_{m d}\left(S, P \rightarrow P_{a}\right)$ will be transformed into $T_{m d}\left(S, P_{\mathrm{a}}\right)=\theta_{m d}\left(S, P_{\mathrm{a}}\right) ; \Delta T_{a d}(T, S, P \rightarrow \mathrm{Pa}) \quad$ will act only on $T(S, P)$ as the adiabatic correction (lapse) to $T_{\mathrm{md}}(S, P)$ at any $P$ equals $\theta(T, S, P)$ identically (the coefficient of thermic extension $\alpha(T, S, P)$ at $T=T_{m d}$ which is included in $\Delta T_{a d}(T, S, P)$ as a cofactor equals 0 ). The equilibrium transition will be observed if the transition is carried out along the $T_{m d}$ line or will be equidistant from the density constancy, $\alpha(T, S, P)$ and other thermodynamic properties of water are preserved (Fig.1).

The analysis of (2a) shows: any points on the line $T_{m d}(S, P)$ are transformed only into a single point $\theta_{m d}\left(S, P_{a}\right)$ with $\Delta T_{a d}\left(T_{m d}, S, P\right) \equiv 0$. The points lying in situ to the right (to the left) of the $T_{m d}(S, P)$ curve after the transformation into potential temperature $\theta(T, S, P)$ are situated to the right (to the left) of $\theta_{m d}\left(S, P_{a}\right)$. As a result, the transformation of (2a) has thermodynamic properties from the $\mathrm{T}$ vicinity in situ to the $\theta$ vicinity taking into account density features of corresponding water densities $\rho(T, S, P)$ and potential densities $\rho^{*}(T, S, P)=\rho\left(\theta, S, P_{a}\right)$. It testifies the equilibrium of the transition $P \rightarrow P_{a}$ performed (Fig.). At $P=P_{a}$ the equation (2) is transformed into (3) where $\theta(T, S, P)=\theta_{m d}\left(S, P_{a}\right)+\theta^{\prime}(T, S, P)$. It again emphasizes that (1) is applicable only for surface waters, i.e. for $P=P_{a}$. While using (1) for $P=180$ bars, the error in the calculation of $\Delta T_{a d}(T, S, 180)$ at $\mathrm{T}<4^{\circ} \mathrm{C}$ may be $0.04^{\circ} \mathrm{C}$ (for $\mathrm{T}>4{ }^{\circ} \mathrm{C}$ and to $30^{\circ} \mathrm{C}-0.4^{\circ} \mathrm{C}$ ). The error for $\theta\left(T, S, 180\right.$ ) calculation reaches $4^{\circ} \mathrm{C}$. It is evidently clear that maximal errors of qualitative and quantitative character in $\theta$ calculation and $\rho^{*}$ are within the range of $T(P)<4^{\circ} \mathrm{C}$; e.g., for deep zone of Lake Baikal (Weiss et al., 1991;

Sherstyankin, Kuimova, 1995; Peeters et.al., 1996) which is given in (Sherstyankin, Kuimova, Potemkin, 1996). We are going to show only one example from Weiss et al. (1991): $T(P=160$ 
bars $=3.08{ }^{\circ} \mathrm{C}$. According to (1), $\theta=3.05{ }^{\circ} \mathrm{C}$; the sign $\alpha(T, S, P)$ changes. According to (3), $\theta(T=3.08, P=160)=6.37^{\circ} \mathrm{C}$ retaining the character of thermodynamic features of surrounding point in situ and on the surface (It is conserving the sign $\alpha$ ).

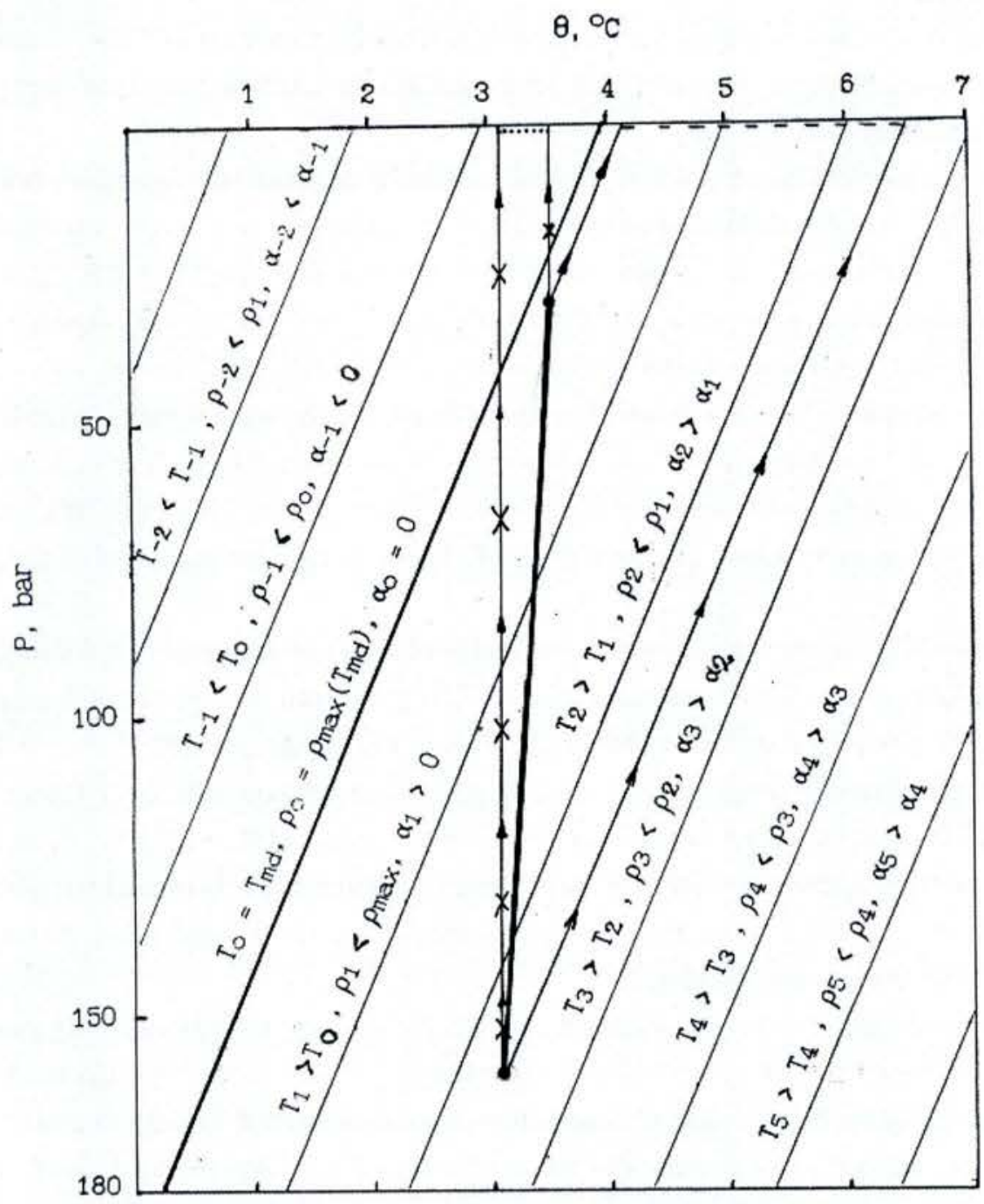

Fig. 1 The example of calculation of potential temperature $\boldsymbol{\theta}$ for equilibrium correct transition from pressure $P$ to $P_{a}$ according to (2) ( $\rightarrow$ ) and for non-equilibrium incorrect transition from pressure $P$ to $P_{a}$ according to $(1)(\rightarrow \mathrm{x} \rightarrow)$ for the equation of water state in the form (Chen, Millero, 1986). The adiabatic correction - Tad is less than the point size. The diapason of changes $\theta(T, S, P)$ for the formala (1) show by the dotted line, for the formala (3) show by the dashed line.

Let us calculate $\rho^{*}(T, S, P)=\rho\left(\theta, S, P_{a}\right)$ according formulae (1) and (3) or $\sigma^{*}=\left(\rho^{*}-1\right) 10^{3}$ and to receive at different $S$, Table 1 .

It is seen in Table 1 that potential temperatures $\theta(T, S, P)$ and potential densities $\rho^{*}(T, S, P)$ between 
the horizons 300 and $1600 \mathrm{~m}$ (30 and 160 bars) calculated using formules (1) and (3) change very strongly. The range of their changes for Baikal water $\left(S=0.096 \mathrm{~g}^{\cdot \mathrm{kg}^{-1}}\right)$ is 0.48 and $2.24^{\circ} \mathrm{C}$ for $\theta$ or $5.210^{-6}$ and $44.810^{-6} \mathrm{~g}^{\prime} \mathrm{cm}^{-3}$ for potential density $\rho^{*}$. It is quite clear the using of formule (1) misinterpret the character of $\theta$ and $\rho^{*}$ vertical distributions.

Table.1.

$\rho^{*}(\mathrm{~T}, \mathrm{~S}, \mathrm{P})=\rho\left(\theta, S, P_{a}\right)$ according formulae (1) and (3) or $\sigma^{*}=\left(\rho^{*}-1\right) 10^{3}$ at different $S$

\begin{tabular}{lllllll}
\hline P, bars & $\theta,{ }^{\circ} \mathrm{C}($ of $(1))$ & $\sigma^{*}, \mathrm{~g} \cdot \mathrm{mm}^{-3}$ & $\mathrm{~S}, \mathrm{~g} \cdot \mathrm{kg}^{-1}$ & $\theta,{ }^{\circ} \mathrm{C}(\mathrm{of}(3 \mathrm{a}))$ & $\sigma^{*}, \mathrm{~g} \cdot \mathrm{mm}^{-3}$ & $\mathrm{~S}, \mathrm{~g} \cdot \mathrm{kg}^{-1}$ \\
\hline 30 & $3.53^{\mathrm{x}}$ & -0.0297 & 0.000 & $4.13^{\mathrm{xxx}}$ & -0.0282 & 0.000 \\
& & 0.0475 & 0.096 & & 0.0488 & 0.096 \\
& & 0.0508 & 0.100 & & 0.0521 & 0.100 \\
\hline 160 & $3.05^{\mathrm{xx}}$ & -0.0351 & 0.000 & $6.37^{\mathrm{xxx}}$ & -0.0724 & 0.000 \\
& & 0.0423 & 0.096 & & 0.0040 & 0.096 \\
& & 0.0455 & 0.100 & & 0.0071 & 0.100 \\
\hline
\end{tabular}

${ }^{\mathrm{x}}$-of Peeters et al.(1996), ${ }^{\mathrm{xx}}$ - of Weiss et al. (1991), ${ }^{\mathrm{xxx}}$ - our calculation

We see that at calculation according to formula (1) we receive more narrow-band potential temperature $\theta$ (less $1{ }^{\circ} \mathrm{C}$ ) than at our calculations according to formula (3) (more $2{ }^{\circ} \mathrm{C}$, Fig.1.) and respectively different potential density $\rho^{*}$ (Table 1 ).

It is possible to obtain the correct conclusion for practical and theoretic problems with the use of potential densities $\rho^{*}(T, S, P)$ only according to (3) which takes into account not only adiabatic correction but also the equilibrium transition in accordance with the equation of water state, i.e. with regard to the properties of molecular structures of water.

\section{Acknowledgements}

Research was supported by grants Russian Foundation of Basic Researches (96-05-65850 and 9605-65997).

\section{References}

Chen, C. T., Millero, F. J. 1986. Precise thermodynamic properties for natural waters covering only the limnological range. Limnol. \& Oceanogr. 31: 657-662.

Gill, A. E. 1982. Atmosphere-Ocean Dynamics. Academic Press,New York, London.

Horne, R. 1969. Marine Chemistry. Wiley, New York-London.

Kamenkovich, V. M. 1973. Osnovy Dinamiki Okeana. Gidrometeoizdat, Leningrad (in Russian).

Peeters, F., Piepke, G., Kipfer, R., Hohmann, R., and Imboden., D. M. 1996. Description of Sta-

bility and Neutrally Buoyant Transport in Freshwater Lakes. Limnol.Oceanogr. 41:17111724.

Phillips, O. M. 1977. The Dynamics of the Upper Ocean. Second Ed., Cambrige.

Sherstynkin, P. P.,Kuimova, L.N. 1995.Thermohalinical Analysis of Mixing Processes and Frontogenesis of Baikal Waters. Doklady Akademii Nauk,Reports RAS,344:247-251 (in Russian). 
Sherstynkin, P. P., Kuimova, L.N., Potemkin, V. L. 1996. Main Features of Thermohaline Regime of Deep Zone Lake Baikal on the Base T,S-Analysis. Doklady Akademii Nauk, Reports RAS.(in press, in Russian).

Vereshagin, G.Yu. 1927. Certain Data on the Regime of Deep Water of Lake Baikal in the Vicinity of Maritui. Trudy Komissii po Izucheniyu Baikala. Leningrad. 2: 77-138 (in Russian).

Weiss, R. F., Carmack, E.C., and Koropalov, V. M. 1991. Deep-water renewal and biological production in Lake Baikal. Nature, 349: 665-669. 